\section{SINTOMAS DE “REGIONALISMO CRÍTICO": SOBRE O "DECORATIVISMO" NA PINTURA DE AMADEO DE SOUZA CARDOSO}

\author{
Joana Cunha Leal \\ Instituto de História da Arte \\ Faculdade de Ciências Sociais e Humanas \\ Universidade Nova de Lisboa \\ j.cunhaleal@fcsh.unl.pt
}

Cómo citar este artículo/Citation: Leal, J. C. (2014). "Sintomas de 'regionalismo crítico': sobre o 'decorativismo' na pintura de Amadeo de Souza Cardoso". Arbor, 190 (766): a113. doi: http://dx.doi.org/10.3989/arbor.2014.766n2005

Recibido: 11 septiembre 2012. Aceptado: 8 octubre 2013.

RESUMEN: Se analiza cómo la historiografía portuguesa dimensionó la relación que la pintura de Amadeo de Souza Cardoso (1887-1918) establece entre las indagaciones internacionales del modernismo y su regional "portugalidad". Somos conducidos así a la idea de que el origen portugués introduce en la obra de Amadeo, por putativa insuficiencia cultural y estética, un ingenuo provincianismo desprovisto de instancia crítica. Ese provincianismo lo haría apropiarse decorativamente de los célebres discos simultáneos de Robert Delaunay. Este artículo pretende discutir esa tesis, procurando demostrar que, lejos de la distorsión que se le atribuye, la apropiación "decorativa" que Amadeo hace de ese elemento se inscribe en un plano de resistencia cercano a la idea de "regionalismo crítico". Sobreviene, por fin, la hipótesis, desarrollada a partir del análisis de una tele de 1917, de que la invisibilidad de tales síntomas de resistencia sea sobre todo deudora de una perspectiva que asocia el modernismo a la superación de la representación en las artes plásticas.

PALABRAS CLAVE: Modernismo; provincianismo; decorativismo; regionalismo crítico; historiografía del arte.

\section{SIGNS OF "CRITICAL REGIONALISM": ON THE "DECORATIVE-STYLE" IN THE PAINTING OF AMADEO DE SOUZA CARDOSO}

Copyright: (C) 2014 CSIC. Este es un artículo de acceso abierto distribuido bajo los términos de la licencia Creative Commons Attribution-Non Commercial (by-nc) Spain 3.0.

\begin{abstract}
This article discusses at its outset the way Portuguese art history acknowledged and debated the relation that Amadeo Souza Cardoso's painting establishes between international modernism and its regional Portuguese provenance. This debate imposed the idea that Amadeo's national origins brought about, by way of the putative Portuguese disregard of main cultural and aesthetic standards, a trace of provincialism, eventually making his work unable of any critical stance. This provincialism is diagnosed on the basis of Amadeo's decorative appropriation of Robert Delaunay's simultaneous color circles. This article discusses this thesis, demonstrating that, far from the reactionary drive associated to it, Amadeo's decorative interpretation of such element must, instead, be understood as a symptom of resistance, one that can be acknowledged as approaching the idea of "critical regionalism". A final hypothesis suggests that the invisibility of this symptom arises from a perspective that associates modernism to the overcoming of representation in art.
\end{abstract}

KEYWORDS: Modernism; Provincialism; Decorativeness; Critical Regionalism; Historiography (of Art History).

"La estrategia fundamental del regionalismo critico consiste en reconciliar el impacto de la civilizacion universal con elementos derivados indirectamente de las peculiaridades de un lugar concreto.

De lo dicho resulta claro que el regionalismo critico depende del mantenimiento de un alto nivel de autoconciencia critica." 
I.

Trazer um conceito da teoria e da cultura arquitectónica, como o de "regionalismo crítico", para a análise da obra de Amadeo de Souza Cardoso (1887-1918) ${ }^{1}$, surge neste artigo como um pretexto para revisitar a obra do pintor, sem dúvida um dos mais relevantes do modernismo português ${ }^{2}$. A proposta que aqui faço não visa a discussão sobre o alcance e a propriedade do uso desse conceito fora do campo da arquitectura. Ela é antes motivada pelo que creio ser uma necessária revisitação dos debates em torno da obra de Amadeo, especialmente da que produziu em Portugal nos últimos anos da sua vida. Ou seja, as telas que pintou entre o deflagrar da 1 a Guerra Mundial (que o impediu de regressar a Paris, onde se estabelecera desde 1907) e as vésperas do Armistício de 1918 (Amadeo morreu em Espinho cerca de um mês antes do termo da Guerra).

Os anos da Guerra são reconhecidos como anoschave na produção de Amadeo de Souza Cardoso. J.A. França dá conta, no estudo inaugural que dedicou ao pintor em 1957, de que esse momento corresponde a uma quebra radical na dinâmica das relações que mantinha em Paris, e que desse centro irradiavam para o resto da Europa e para os Estados Unidos (cf. Silver, 1999, 51-59). Sublinha, no entanto, que "o fio das experiências" não foi interrompido ${ }^{3}$. Mais recentemente, M. Helena de Freitas acentua o facto de o pintor ter encontrado uma compensação no "virar de página" que a Guerra representou:

"A abafar dentro dos limites geográficos impostos pelas suas montanhas e no contexto do arrefecimento mundano provocado pelo horror da guerra, Amadeo concentra-se na sua pintura. É na produção realizada a partir de então que lhe podemos reconhecer maior energia e criatividade individual” (Freitas, 2006, 53)

Precisamente nestes anos Amadeo fará as suas únicas exposições individuais, mostrando os seus trabaIhos, em Dezembro de 1916, no Porto, e depois em Lisboa, no Salão da Liga Naval. Finalmente, e este será um dado central para a discussão que pretendo desenvolver, este foi também o período de uma intensa relação com Robert e Sonia Delaunay. Como bem se conhece, a permanência de Amadeo entre a quinta de Manhufe e a praia de Espinho não correspondeu exactamente a um retiro cartuxo. O seu isolamento foi largamente quebrado pelo contacto com os Delaunay que, em 1915, a Guerra fizera também aportar a Lisboa e fixar-se em Vila do Conde. O círculo das relações de Amadeo recuperou, por essa via, o pintor português Eduardo Viana e em breve se alargaria a Alma- da Negreiros ${ }^{4}$, tendo este núcleo de amizades gerado diversos projectos. O mais relevante desses projectos seria a ideia de uma Corporation Nouvelle destinada a promover exposições internacionais itinerantes onde o trabalho dos pintores portugueses e dos Delaunay seria acompanhado pela poesia de Apollinaire e Blaise Cendrars (cf. Ferreira, 1972 e O'Neill, 1999, 61-77).

As expectativas do pintor nesses anos voltaram-se igualmente para a criação de uma obra que, com Sonia e à semelhança do que esta já criara para a Prosa do Transiberiano, acompanhasse a poesia de Cendrars (cf. Ferreira, 1972).

Tais projectos nunca chegaram a concretizar-se, deixando Amadeo insatisfeito com a falta de interesse do casal Delaunay para levar a bom termo estas iniciativas conjuntas. Especialmente castigador foi o incumprimento da exposição do colectivo da Corporation Nouvelle agendada para Barcelona, para a qual Amadeo chegara a enviar uma série de telas aos Delaunay. Como sintetisa Rosemary O'Neill:

"In a series of letters in May 1916, Souza Cardoso urged the Delaunays to exhibit in Barcelona. He sent five of his works to them in Vigo on 13 May in hopes the exhibition would be realized (...). But Sonia and Robert Delaunay had already sent their works in April to Stockholm for an exhibition at the Nya Konstgalleriet. Over the next two months, Souza Cardoso pressed them to return his works if the exhibition in Barcelona proved unfeasible. Souza Cardoso acknowledge the return of his paintings in a letter dated 11 July 1916, but this incident strained their friendship." (O’Neill, 1999, 75-76).

II.

Os sintomas de "regionalismo crítico" que trago para título deste artigo apelam à observação e discussão de um outro problema, que vem a ser o da relação, o do encontro-confronto, entre as pesquisas internacionais do modernismo que Amadeo acompanhou, e a referência ao seu remoto lugar de pertença, ou seja à sua regional "portugalidade". Esta questão é, como veremos, central num dos debates mais sérios que sobre a pintura de Amadeo se $f e z^{5}$. Protagonizado por J.-A. França, esse debate reporta-nos à ideia de que origem portuguesa introduz na obra de Amadeo, por insuficiência cultural e estética, um ingénuo provincianismo desprovido de instância crítica. Esse provincianismo fá-lo-ia apropriar-se de elementos centrais da pintura de Robert Delaunay, concretamente os discos simultâneos, decorativamente. 
Este artigo pretende discutir essa tese, procurando demonstrar que, longe do reaccionarismo que França Ihe atribui ${ }^{6}$, a apropriação que Amadeo faz desse elemento se inscreve num plano de resistência aproximável da ideia de regionalismo crítico $^{7}$. Esta discussão não partirá, por isso, das representações do colorido folclore minhoto que povoam as telas de Amadeo e deram margem à elevação da sua pintura no quadro da política cultural do Estado Novo. É que, como desde logo adverte Kenneth Frampton, há que distinguir a perspectiva do regionalismo crítico das fórmulas de gratificação garantidas do populismo, ou nas suas palavras:

\begin{abstract}
"es necesario distinguir entre el regionalismo critico y los ingenuos intentos de revivir las formas hipotéticas de los elementos locales perdidos. El principal vehiculo del populismo, en distinción por contraste con el regionalismo crítico, es el signo comunicativo o instrumental. Este signo trata de evocar no una percepción crítica de la realidad, sino más bien la sublimación de un deseo de experiencia directa a través del suministro de información. Su objetivo táctico es conseguir, de la manera más económica posible, un nivel preconcebido de gratificación en términos de comportamiento. A este respecto, la fuerte atracción del populismo por las técnicas retóricas y la imaginería de la publicidad no es en modo alguno accidental. A menos que uno se proteja contra semejante contingencia, confundirá la capacidad de resistencia de una practica crítica con las tendencias demagógicas del populismo." (Frampton, 1985, 44-45)
\end{abstract}

Vejamos então os termos da questão.

Quando, na década de 1960, José-Augusto França lança a discussão sobre a "portugalidade" de Amadeo fá-lo assumindo uma cuidadosa distância em relação à sua apropriação pelo Regime. As suas considerações tomam como ponto de partida a apreciação que, em 1925, António Ferro (o futuro responsável pela política cultural do regime de Salazar) fez da sua obra. Nas palavras de Ferro, Amadeo é "o grande percursor" que, tendo tomado "a sério" o cubismo em 1912 "Nunca deixou de ser português. Através da geometria intencional dos seus quadros, através do colorido berrante da sua arte, adivinhava-se Portugal, o alegre Portugal das Romarias, dos bairros populares, do céu azul, dos trajos festivos..." (Ferro, 1925)

A resposta de França à versão populista da portugalidade de Amadeo é largamente enfatizada na 3 a edição do estudo pioneiro que dedicou ao pintor e que surge com o título Amadeo de Souza-Cardoso: o português à força ${ }^{9}$. França consolidava assim o seu distanciamento em relação ao "nacionalismo caseiro que a certa altura (...) pretendeu tomar Amadeo à sua conta", e que encontrava "até, nas palavras de Almada Negreiros (...), achando que toda a sua arte reflecte o seu rincão natal". A ser português, Amadeo só o poderia ter sido "à força", no quadro da leitura alimentada pela "imagística oficiosa" do Regime de Salazar (França, 1985 [1957], 14-15).

Mas o estudo de França vai mais longe. Para o historiador, a questão da portugalidade de Amadeo não se detinha realmente na percepção da sua obra como representando signos de identidade (conteúdos populares, colorido berrante) que o Regime convertera alegremente numa narrativa nacionalista. Tal como vinha sendo formulado desde os anos 1960, o problema ganha uma dimensão mais profunda, estruturante, que implicava sobretudo reconhecer a "portugalidade" de Amadeo como introduzindo uma importante falha no seu projecto pictórico. Como antecipei, Amadeo seria português graças à manifesta e fatal incapacidade de superar a sua pertença regional, o seu provincianismo ${ }^{10}$. França sublinha, pois, a ideia de que o pintor não cumpriu a expectativa que o seu percurso internacional legitimara ${ }^{11}$. Os eixos centrais desta tese surgiam já bem identificados nas páginas da revista Colóquio: revista de artes e letras (França, 1968, 17-20) e são plenamentamente desenvolvidos na 2 a edição do estudo que dedica a Amadeo, publicada então com o título Amadeo ou o Século XX (1972). Estávamos já longe das primeiras leituras da obra de Amadeo como "1a descoberta de Portugal no século $\mathrm{XX}^{\prime 12}$, essas mesmas que tinham autorizado a apresentação do pintor como representante único de "uma modernidade autêntica, quer dizer, como consciência pictural ajustada às exigências da contemporaneidade"13 e que continuarão a ecoar na historiografia posterior.

A tese da falha de Amadeo domina o último capítulo das reedições do estudo que venho citando. Nele o historiador ultrapassa a síntese do debate feita em 1968, para dar à questão uma dimensão histórica mais aprofundada e agravar o tom da sua crítica. Neste capítulo, intitulado "Amadeo ou a Lenda da Arte Moderna Portuguesa", França abre interrogações centrais: "Poder-se-á a propósito [de Amadeo] falar dum evolutivo 'cubismo português' (...)?" e "Esse cubismo 'a posteriori', que cubismo realmente foi? Que dose de inspiração portuguesa, mesmo que posta em marcha pelos Delaunays das feiras e naturezas-mortas minhotas, nele entrou em cores, desordem e alguma possível alegria de férias, embora forçadas?" (França, 1985 [1957], 144). 
Para o historiador a conclusão é clara:

"Nacionalizar parcelarmente um movimento estético é reduzi-lo num processo de adjectivação que ele deve repudiar para se definir; mas verdade é que cada cultura tem jeitos nacionais que se impõem na franja "kitsch" que lhe é reservada com maior ou menor gosto, sensibilidade e inteligência. Assim em termos metódicos de hipótese, se pode admitir que se passou com o cubismo que, a certa altura, Amadeo praticou." (Idem)

França classifica o encontro de Amadeo com os desenvolvimentos internacionais do cubismo como uma apropriação defeituosa, incompleta e justificável pela inadequação genética de uma posição periférica, regional, em relação ao lugar central, justo, que outros pintores ocupariam (estranhamente Juan Gris é um exemplo mencionado). Esta sua perspectiva está directamente associada ao perfil assimétrico que atribui à relação de Amadeo com os Delaunay, muito particulamente com Robert Delaunay. Esta assimetria é um dado fundamental no argumento que aqui me proponho desenvolver a partir da análise que França faz da apropriação por Amadeo dos célebres discos órficos.

Na narrativa de J.-A. França, a obra de Robert Delaunay é apresentada como território de pesquisas pictóricas centrais (geográfica, histórica e esteticamente falando), pesquisas que a apropriação periférica, kitsch, estaria destinada a distorcer, como acontece no caso da obra de Amadeo (mas também, como acabará por reconhecer, no caso de Sonia Delaunay). E o primeiro sinal dessa distorção surge logo em 1913, ano em que Amadeo conheceu os Delaunay: as telas abstractas que então pintou - "meia dúzia de obras em que a cor vivia exaltadamente" - ecoam já as "ideias picturais" do pintor francês, e incorporam pela primeira vez os seus discos, mas não atingem as suas "reverberações luminosas" (e bem, o valor estético que reconhece a estes últimos) ${ }^{14}$.

Essa aproximação à "via delaunayana" viria a ser retomada por Amadeo no período de comunhão do exílio da Guerra no Norte de Portugal. É a partir de 1915 que os discos simultâneos entram em força na sua pintura. J.-A. França dá bem conta desta assimilação, chamando desde logo a nossa atenção para os "vários graus de uso e de significado compositivo" que os discos vão adquirindo nas sucessivas telas de Amadeo: "Quadro a quadro, (...) os 'discos' [inserem]-se nas composições, pontuandoas com a sua vibração cromática, assim intervindo na unidade e na variedade da figuração. Enfeite de avental ou articulação de braço, alvo ou sinal no espaço" eles vão povoando os trabalhos, assumindo sempre, e isto é absolutamente fundamental, uma dimensão, um carácter, que classifica como decorativo (França, 1985 [1957], 139).

O termo decorativo vem, na tradição historiográfica de J.-A. França, impregnado do sentido pejorativo que o projecto da Arquitectura Moderna muito contribuiu para consolidar, mas que sobressai, logo em 1912, na versão que Gleizes e Metzinger dão do próprio cubismo, ao tomar o trabalho decorativo como antítese da pintura ${ }^{15}$. Entende França que nas telas de Amadeo os discos adquiriram um estatuto decorativo - i.e. dependente ou ao serviço do que por meio deles se representa: avental ou articulação de braço, alvo ou sinal no espaço - em oposição à situação funcional-estrutural, entendida como estritamente auto-referencial, que atribui aos originais de Delaunay, "fisicamente agenciados para traduzir uma análise espectral da luz" (Idem) ${ }^{16}$. Essa oposição é, crê, assimétrica. Ou seja, trata-se antes do mais de um "deslizamento de funções" que J.-A. França é muitíssimo eficaz em elucidar:

"Assim se verifica um deslizamento de funções, senão uma contradição delas: aquilo que era, por via da luz-agente, essencial à composição, seu elemento estrutural, passou a ser, quando a luz deixa de ter papel no quadro, seu elemento decorativo. O "disco" de Delaunay, patenteado no âmbito de uma determinada diligência pictural, viu-se perdido ou achado em outra situação que dele fazia outra coisa." (França, 1985 [1957], 139)

Semelhante deslizamento é equacionado no âmbito de uma moldura crítica talhada não só para distinguir a função estrutural da decorativa (i.e. suplementar, adicional), mas também para valorizar a primeira e desvalorizar a segunda, numa elaboração discursiva que joga a lógica bipolarizadora de oposições "clássicas" como profundo/superficial, estrutural/ decorativo (ou ornamental) ou original/cópia (e que se estende ainda, noutros contextos, por exemplo, à distinção entre forma/matéria ou forma/conteúdo). Donde, e necessariamente, a apropriação que Amadeo faz dos discos delaunayianos está situada no pólo negativo do par e o seu deslizamento é, seguindo o mote, descendente. O que aparentemente poderia minorar a derrocada total de Amadeo acresce, afinal, para França, à falha irremediável do seu projecto pictórico. É que Amadeo não teve consciência desse deslizamento por "superficialidade de acção", ou nas palavras do historiador: 
“Amadeo não teve, com certeza, consciência disso: o entorce fundamental que imprimiu a um elemento gramatical, subordinando-o a um outro jogo semântico, foi-lhe indiferente, na medida em que não precisava dele tal como o seu mestre ocasional precisava. Por superficialidade de acção? Sem dúvida - mas, não Ihe sendo própria aquela que Delaunay definia e realizava, como censurar-Ihe o procedimento? Na verdade Amadeo limitou-se a fazer seu um bem alheio, sem espírito de discípulo como sem plágio. E não foi o único a fazer assim." (Idem) ${ }^{17}$

É então que, seguindo a mesma lógica antinómica, reencontramos em força o argumento da oposição centro/periferia, o argumento que contrasta a inadequação da proveniência regional de Amadeo ao lugar central das pesquisas que um pintor como Robert Delaunay legitimamente asseguraria e que o distancia tanto do pintor português, quanto, crê França, do trabalho de sua mulher Sónia (cuja origem "russa" é então sublinhada): "O que aconteceu foi, imediatamente, uma coisa muito simples: ser francês Delaunay e não o ser qualquer dos outros..." (França, 1985 [1957], 140) ${ }^{18}$.

Assim justifica J.-A. França a maior proximidade de Sónia com os artistas portugueses (que para além de Amadeo incluíam, em estreita proximidade, Eduardo Viana): alheios ao "Iuminismo próprio de Delaunay", souberam acordar o "valor decorativo dos 'discos' (...) com certo gosto nacional, dum folclore alto de cores, onde vibravam ainda lembranças de bailados, passados dos anos de antes da guerra para os do pós-guerra (...) que, de um modo ou de outro, o 'disco'-sinal simbolizava, em gestos de 'sport' ou de aviação..."19

Como já se adiantou, não foi a valorização de referentes nacionais, como o colorido do folclore, que França converteu em motivo de análise e discussão na obra de Amadeo. Antes, o "portuguesismo" de Amadeo revelaria um desajustamento estrutural (ou mesmo orgânico) da sua prática pictórica, particularmente agravado pela superficial e desmedida ambição do pintor. Assim, o trabalho de Amadeo é contrastado com a genuinidade do compromisso naturalista, e com a modéstia certeira, que o historiador encontra na obra de Eduardo Viana ${ }^{20}$, tal como é contrastado, no pólo oposto, como vimos, com a modernidade estruturada e sólida que encontrara em Robert Delaunay. No primeiro caso, Amadeo estaria "fora de jogo" por conta da sua formação parisiense e da sua ambição desmedida, no segundo por irremediável "insuficiência portuguesa". Voltamos pois ao início, porque o decora- tivismo dos discos de Amadeo encontraria, como vimos, a sua raiz na incapacidade do pintor em superar a sua pertença regional.

Uma última nota "encerra" a crítica de J.-A. França: o facto desse decorativismo, em toda a sua superficialidade, com todo o grau de inconsciência pictórica que o historiador Ihe atribui, justificar igualmente a incessante experimentação do pintor. A voragem com que Amadeo aborda diferentes propostas pictóricas - é célebre a fórmula como se apresenta na entrevista ao jornal O Dia de 4 de Dezembro de 1916: "Impressionista, cubista, futurista, abstraccionista? De tudo um pouco." - sem de qualquer delas retirar a possibilidade de construção de uma (putativamente desejável) coerência estética ou de inscrição num (putativamente existente) discurso interno da pintura, é lida como uma rendição à "admiração exterior", ou "espanto provinciano" (França, 1968, 19). Como escreve:

"O ritmo desta evolução de Amadeo pelas etapas da pintura ocidental não pode deixar de nos preocupar. Ela traduz, sem dúvida, uma ambição, mesmo uma avidez que é contrária a grande empenho de consciência estética. Se isso é inegavelmente, uma característica do próprio artista (e cada qual é como é...), pode também ser tomado como uma característica de pintor português então subitamente lançado nas encruzilhadas da modernidade, sem preparação anterior, sem 'tempo' próprio que o proteja de uma admiração exterior - senão de um espanto provinciano." (França, 1985 [1957], 141)

Impossível ler estas palavras sem as remeter para Fernando Pessoa quando declara, em 1928, o provincianismo como "mal superior português" e o define como consistindo "em pertencer a uma civilização sem tomar parte no desenvolvimento superior dela - em segui-la pois mimeticamente, com uma subordinação inconsciente e feliz." (Pessoa, 2001 [1928], 371) ${ }^{21}$. Pessoa esclarece ainda os três sintomas flagrantes do provinciano: "o entusiasmo e admiração pelos grandes meios e pelas grandes cidades; o entusiasmo e a admiração pelo progresso e pela modernidade; e na esfera mental superior, a incapacidade da ironia."

III.

O enquadramento crítico que J.-A. França dá à obra de Amadeo (reitero aqui que França é, de entre os historiadores da arte portugueses, um dos que mais profundamente olhou e debateu a obra deste pintor) foi directamente questionado, pela primeira vez, por 
Eduardo Lourenço. Ainda que brevemente, o autor de $O$ Labirinto da Saudade discutiu a tese da falha de Amadeo, do "reflexo arquétipo de Amadeo", num pequeno ensaio que permaneceu inédito até 1981, intitulado "Os círculos dos Delaunay ou o estatuto da nossa pintura" (Lourenço, 1981, 127-137). O texto remete-nos para a tese da "apropriação de uma técnica e de um motivo sem a motivação" por parte do pintor português, mas fá-lo introduzindo uma interrogação necessária à sua (ainda tímida) problematização:

\begin{abstract}
"Mais do que uma secreta impotência, estará eivado o nosso reflexo pictural próprio de algum vício estrutural ou será antes a leitura discutível da nossa produção artística (e cultural) que nos inculca a ideia do seu carácter marginalizante? A óptica com que nos julgamos parece não deixar ou consentir ilusões: é sempre de um ponto ideal, extrínseco à nossa aventura histórica específica que a mais dinâmica crítica de arte se situa para apreciar e situar as propostas sucessivas da nossa Pintura." (Idem, 133)
\end{abstract}

Esta ideia de que poderá haver uma "leitura discutível" da nossa produção artística, de que estamos presos a uma perspectiva que não nos permite ilusões porque corresponde invariavelmente a um ponto de vista ideal e externo, foi trabalhada nos anos 1990 para o largo espectro da cultura portuguesa por Boaventura Sousa Santos ${ }^{22}$ :

\begin{abstract}
“Na ausência de adequada inovação teórica, corre-se o risco de analisar a sociedade portuguesa pela negativa, por aquilo que ela não tem quando comparada quer com as sociedades centrais, quer com as sociedades periféricas. Tal negatividade é uma outra forma de desconhecimento e por isso também campo fértil de análises míticas e estipulações de exotismo, que são neste caso feitas da inadequação dos instrumentos analíticos" (Santos, 1994, 53)
\end{abstract}

No campo da historiografia da arte esta advertência tem sido ignorada. Como esclarece Mariana Pinto dos Santos, o discurso historiográfico português tem-se pautado por duas posturas só superficialmente antagónicas:

"a que afirma um atraso crónico na arte portuguesa e a que afirma uma especificidade na arte portuguesa. Só na aparência são antagónicas porque na verdade justificam-se e alimentam-se uma à outra: caricaturizando, a arte está atrasada, logo estamos isolados ou à parte do centro onde tudo anda sobre rodas numa evolução perfeita, esse isolamento torna a nossa arte especial e com características essenciais, que por vezes até produzem epifenómenos equiparáveis ou mesmo precursores do que se passa lá fora (...). Subjacentes a estas posturas permanece um modelo operativo de história enquan- to evolução linear. Um modelo actualmente sujeito a problematização em introduções, mas sem que esta se reflicta no trabalho historiográfico propriamente dito." (Santos, 2010)

Esta articulação entre o atraso provinciano e a especificidade portuguesa ganhou, apesar de tudo, no discurso de J.-A. França sobre a obra Amadeo de Souza Cardoso uma espessura dada pela leitura formal das obras e pelo seu empenho em discutir o enquadramento, ou desenquadramento, estilístico da sua pintura. Como vimos, França segue uma lógica bipolarizadora que assentou os seus pressupostos críticos na desvalorização do uso decorativo que Amadeo faz dos discos órficos de Robert Delaunay. Para França, como também vimos, Amadeo incorreu no provincianismo definido por Fernando Pessoa, ou seja, a relação assimétrica que teria establecido com a obra de Delaunay elucidaria o facto de "pertencer a uma civilização sem tomar parte no desenvolvimento superior dela" (Pessoa, 2001 [1928], 371).

É precisamente a ideia da assimetria desta relação que importa aqui desmontar (1) num plano histórico, mais genérico, discutindo para tanto a hipótese de Boaventura de Sousa Santos, e (2) num plano pictórico, recorrendo para tanto à leitura de uma das obras mais emblemáticas da produção tardia de Amadeo - Entrada, 1917 (obra que venho mantendo sob observação continuada e, por assim dizer, privilegiada).

A trabalho de Boaventura Sousa Santos opera no sentido de desmistificar a pertença regional portuguesa, seja na versão periferização e do atraso, assumida até às últimas consequências pela formulação de França, seja na versão de uma mitificada psicologia nacional ${ }^{23}$. A sua hipótese de trabalho assenta na ideia de que "a cultura portuguesa é uma cultura de fronteira"

\footnotetext{
"não porque para além de nós se conceba o vazio, uma terra de ninguém, mas porque de algum modo o vazio está do lado de cá (...). E é por isso que no nosso trajecto histórico cultural da modernidade fomos tanto o Europeu como o selvagem, tanto o colonizador como o emigrante. A zona de fronteira é uma zona híbrida, babélica, onde os contactos se pulverizam e se ordenam segundo micro-hierarquias pouco susceptíveis de globalização. Em tal zona são imensas as possibilidades de identificação e de criação cultural, todas igualmente superficiais e igualmente subvertíveis (...)" (Santos, 1994, 134) $)^{24}$
}

A fronteira oferece um espaço-tempo de negociação, maleável, que confere à cultura portuguesa 
"um enorme cosmopolitismo", precisamente porque a ausência de um centro identificável nos permeabiliza, impedindo, e aqui chego a um ponto fundamental, a consolidação do provincianismo que só uma homogeneização pode garantir ${ }^{25}$. Esta proposta é contrária à definição pessoana do provincianismo como "mal superior português" que J.-A. França acarinhou. O próprio autor nos dá conta do seu desacordo com a tese de Fernando Pessoa porque, sendo embora a descrição do "sintoma" exacta em termos gerais, ela não se acorda com a dimensão fronteiriça da cultura portuguesa. "Em meu entender", escreve Boaventura Sousa Santos,

"o elemento barroco da cultura portuguesa faz com que a mimesis da 'civilização superior' ocorra sempre com uma distância lúdica e um espírito de subversão, selectiva, superficial e ambiguamente combinados com a dramatização do próprio, do vernáculo, do genuíno." (Santos, 1994, 134-135)

Uma outra hipótese vem reforçar esta ideia e, do ponto de vista em que construo a minha perspectiva, merece ser cuidadosamente analisada. Trata-se da ideia de que, para além do acentrismo e do cosmopolitanismo, a "dramatização e carnavalização das formas" são características da forma cultural de fronteira própria dos portugueses. O essencial não está, agora, na constatação de que as apropriações e incorporações culturais tendem a identificar-se mais com as formas do que com os conteúdos dos produtos incorporados, mas na afirmação de que a descolagem entre forma e conteúdo gera "uma atitude de distanciação mais lúdica do que profiláctica, mais feita da consciência da inconsequência do que da consciência da superioridade." (Santos, 1994, 135)

Tal separação entre formas e conteúdos incorporados está, apesar do sentido pejurativo que pode atribuir-se a expressões como "carnavalização das formas" 26 , longe de nos remeter de novo para a tese de J.-A. França sobre o entorse e o desfazamento com que Amadeo apropria os discos de Robert Delaunay. Noções como as de "distanciação lúdica", "espírito de subversão", "consciência da inconsequência", "selectiva, superficial e ambiguamente combinados com a dramatização do próprio, do vernáculo, do genuíno" que Ihe estão associados, minam completamente a base da acusação de deslumbramento assimétrico e espanto provinciano (de incapacidade de ironia, na versão pessoana) que alicerçam a tese de França.
Esta questão é central no meu argumento, desde logo porque o regionalismo associado ao local de pertença de Amadeo deixa de poder ser pensado como falha para gerar, pelo contrário, potência crítica. E o conceito de regionalismo crítico convocado logo no início deste artigo surge exactamente para iluminar essa potência, apto que está a clarificar os sintomas de resistência que creio observar nos novos conteúdos (o decorativismo) que formas estabelecidas (os discos órficos) adquirem na pintura de Amadeo. Na realidade, a noção de regionalismo crítico permitenos ir muito mais longe do que a própria formulação de Boaventura Sousa Santos, na medida em que, como bem demonstra Pedro Vieira de Almeida, defendendo a pertinência do conceito enquanto ferramenta crítica ${ }^{27}$ :

"A formulação avançada por Frampton, ainda que a questionemos, desde logo pressupõe a não existência de qualquer centralidade ou marginalidade. É a própria noção de 'centralidade cultural' e 'marginalidade cultural' que fica posta em causa." (Almeida, 2007, 87)

Aquém do lugar de fronteira em que, aceitando a hipótese de Boaventura Sousa Santos, a pintura de Amadeo se situa ${ }^{28}$, importa ainda notar que a distância negativa que França considerou como puro desajustamento face ao cubismo internacional, decorre, antes de mais, de um enquadramento teórico que faz corresponder a uma forma um único conteúdo e onde, portanto, o efeito de distanciação não pôde ser concebido como potência crítica ou resistência ${ }^{29}$. O esquema a que França submete o entendimento da história cultural portuguesa, neste caso da pintura, transporta-nos a uma narrativa tida como única e necessária. É uma narrativa e que se firma em pressupostos dados como internos, autónomos, compondo uma moldura de pensamento que se apresenta naturalizada. Pressupõe, nessa mesma lógica, a absoluta imparcialidade do historiador-crítico.

Como é reconhecível, encontramos aqui as bases do paradigma epistemológico moderno, a partir do qual se consolidou a base valorativa da crítica e da historiografia da arte ao longo de praticamente todo o século XX (cf. Krauss, 1985 e 1996). Encontramos também, como seria de esperar, o essencialismo e o pressuposto de auto-referencialidade centrais para a crítica modernista que colocou a abstracção como destino maior da história da pintura (no discurso de França, não obstante, não encontramos a noção greenberguiana central da especificidade do medium). Os escritos que nos ocupam, propõem uma ideia de 
pintura moderna que, por um lado, parece cativa dos constragimentos gerados pelo contexto histórico português (porque a defesa do modernismo foi bandeira da política cultural do Estado Novo pela mão de António Ferro) $)^{30}$. Fixam-se, por outro lado, na plena consagração da ideologia do novo e da auto-referencialidade pictórica, seguindo uma lógica teleológica e de afirmação de oposições binárias comuns (estrutural/ ornamental, superficial/profundo, original/cópia, centro/periferia). Desta se pode dizer que ignora tanto a fundamental arbitrariedade dos termos em questão quanto a sua constante negociação no discurso. Só num universo assim concebido se pode admitir que a re-funcionalização dos dicos órficos ao serviço da representação por Amadeo - o que França classifica como decorativismo e opõe à situação funcional-estrutural de tratamento da luz que ocupam na pintura de Robert Delaunay - caia fora do campo central de pertinência da história da pintura moderna, e dos desenvolvimentos do cubismo em particular.

Mais se poderá notar, num breve parentesis, que, apesar de privilegiar uma história sociológica da arte (França, 1997 [1974]), França ignora a dimensão "babélica" que o modernismo internacional convoca na sua explosão pré-Guerra, feito como foi do encontro de artistas das mais variadas proveniências ${ }^{31}$. A preponderância dos artistas imigrados terá aliás, defende David Cottington, contribuído significativamente para a afirmação da ideia de l'art pour l'art em que a concepção de França se filia ${ }^{32}$.

No lugar de fronteira em que por hipótese a pintura de Amadeo se situa, o que finalmente se evidencia é uma constante negociação dos termos no discurso. É isso que, finalmente, nos mostram os discos órficos apropriados por Amadeo. Os discos pintados são convertidos num elemento de representação - i.e. referenciam algo que lhes é exterior pela negociação da sua condição de signo - fruto de uma apropriação autoconsciente e crítica que afirma o distanciamento (lúdico) tanto em relação a um certo entendimento da pintura (o de Delaunay) quanto à trama de uma experiência vivida (com Delaunay). É isso que uma tela como Entrada (1917) nos dá a ver.

\section{IV.}

Escrevi já longamente sobre Entrada (Leal, 2010) debatendo tanto os constragimentos da análise formalista de J.-A. França (1985 [1957]), quanto os desenvolvimentos semióticos dessa análise protagonizados por P. Lapa (1999). Não se tratava, como não se trata agora, de desmerecer o potencial e a pertinên- cia de tais enfoques, mas de questionar o isolamento, legitimado pela ideia de auto-referencialidade como fim da pintura, que essas leituras desenharam em torno da obra de Amadeo, condenando-se a um empobrecimento, ou mesmo à cegueira ${ }^{33}$. Em questão está o modo como historiadores e os críticos se recusaram ver e analisar as relações que a pintura entretece com o mundo que a rodeia, mesmo tendo por objecto de estudo pinturas-colagens que incorporam objectos desse mundo "exterior", como é o caso de Entrada.

Vinha tudo isto a propósito da ideia de que a 1a Grande Guerra foi um dado fundamental no percurso de Amadeo Souza-Cardoso, dado que a historiografia, começando embora por sublinhar, rapidamente descarta como se de um factor absolutamente periférico se tratasse (cf. França, 1985 [1957] e Freitas, 2006). A constatação de que os anos da Guerra foram particularmente férteis para o trabalho de Amadeo não traduziu nunca senão a ideia de que esses anos favoreceram pesquisas formais totalmente independentes de factores contextuais, que descartam consequentemente a possibilidade de assumir essas formas como instâncias de representação. Tal situação é exemplarmente demonstrada pelas telas de Amadeo escolhidas para integrar a exposição 1914! La Vanguardia y la Gran Guerra comissariada por J. Arnaldo para o Museu Thyssen-Bornemiza (Arnaldo, 2008). Entrada não constou da selecção exposta. Trata-se, porém, de uma tela que incorpora uma série de signos legíveis como referenciando a "entrada" de Portugal e dos Estados Unidos na Guerra, incluindo o episódio da extraordinária acusação de espionagem que, nesse contexto, recaiu sobre Sonia Delaunay, episódio em que Amadeo esteve fortemente envolvido, responsável maior que foi pela defesa de Sonia (cf. Ferreira, 1972).

Remonta-se assim aos primeiros dias Abril de 1916, quando um denunciador dá como certa, a troco de 3000 francos de recompensa, a passagem de informação encriptada por Sonia Delaunay aos submarinos alemães situados ao largo do Atlântico a partir, precisamente, dos discos simultâneos que integravam as suas pinturas. Entrada mostra-nos a torre e o periscópio de um submarino com as cores alemãs - ambos enquadrados pelo jacto de luz que nasce no centro da composição -, e trás também a sugestão de um interior, iluminado por uma lâmpada eléctrica (desenhada a partir do catálogo da Wotan) ${ }^{34}$, separado da escuridão nocturna pelas linhas horizontais de uma persiana dourada. Mostra-nos igualmente os discos que motivaram a acusação, para além de incorporar a palavra "entrada" que deu nome à tela (na realidade, sem título). Mesmo os números 
que Amadeo inscreve no topo da tela parecem remeter para a soma atribuível ao acusador. Lá está também, e aqui reencontro o jacto de luz central na sua fonte, o perfil de um transatlântico desenhado sobre fundo azul, muito possivelmente o célebre Lusitania - as cores da bandeira nacional pintadas sobre um rectângulo de vidro inscrustrado no casco sugerem o nome do barco inglês -, com as suas imponentes quatro torres (duas pintadas, as restantes duas evocadas pelo o número 2) afundado por um submariano alemão, num episódio trágico que despoletou a intervenção militar dos EUA na Guerra. Porém, é bom não esquecer que a própria entrada de Portugal na Guerra esteve, no imediato, associada à nacionalização dos barcos alemães retidos nos portos portugueses desde o início do conflito.

Em nenhum momento a sequência metonímica destes elementos-fragmentos fica cativa ou se esgota na composição de uma montagem narrativa. Não é só o facto da imagem da persiana dourada poder ser também legitimamente classificada como a representação das cordas de um instrumento musical, ou o facto do perfil do Lusitânia configurar também o aspecto de uma qualquer máquina (Santos, 1999: 176), ou ainda o facto da palavra entrada poder ter sido "extraída de uma sinalética de praça de touros" (Gonçalves, 2006, 27) ou de uma casa de espectáculos, porque, na realidade, esta obra assimila um conjunto significativo de outros elementos que não é possível associar (ou que é muito difícil associar) ao contexto dos episódios narrados. Refiro-me particularmente a uma série de signos recorrentes nas obras de Amadeo mais directamente ligadas ao legado do cubismo: a viola e a sugestão de um violino, naturezas-mortas pintadas como se de papiers collés se tratassem, letras e números desenhados a pochoir, um fragmento colado de um papel decorativo de parede.

Negociando os termos do discurso, os signos convocados não cessam além do mais de nos lembrar que a representação, assuma ela um carácter metafórico, metonímico ou literal, conte ela, ou não conte uma história, é neste caso, antes de mais, pintura. Temos em Entrada uma pintura-colagem onde os planos, as técnicas e as texturas - que dão espessura às cores com empastelamentos ou pela mistura de areias nas tintas - variam numa lógica de acumulação que não deixou nenhum vazio e que admite, para além disso, cortes, sobreposições e ocultações desses mesmos planos. As relações positivas e as oposições que entre si estabelecem planos e signos reporta-nos, finalmente, como aliás maioria das pinturas produzidas neste periodo final da vida de Amadeo, para a assimilação do cubismo não como estilo estabelecido, mas como problemática aberta sobre o sentido e as possibilidades da representação e da pintura.

A narrativa que Entrada nos oferece, (des)organizada a partir de elementos-fragmentos que nos reportam a um universo de referências contextuais, reclama a dimensão contextual da portugalidade de Amadeo integrando-a num movimento mais vasto de revisão sobre o sentido e as possibilidades da representação e da pintura. Apenas tomando o abstraccionismo como destino da pintura se poderá, pois, considerar que enferma de algum tipo de entorce ou assimilação periferizadora. E note-se que, como vimos, o que estava em jogo no discurso de J.-A. França era nada mais do que a deslocação dos discos simultâneos para uma função que os arredava da sua "superior" referência lumínica para um campo onde se materializava precisamente uma função representativa.

Assim, embora concordando com o historiador quanto à ideia de que a discussão da portugalidade de Amadeo não deve ser acantonada na constatação de que a sua obra incorpora signos de identidade (conteúdos populares, colorido berrante), recuso liminarmente quer a ideia do desfazamento e da ingenuidade de Amadeo, quer a ideia da assimetria da relação que o pintor português estabelece com Robert Delaunay. Em primeiro lugar, e mais decisivamente, porque recuso a lógica valorativa (e preconceituosa) que condena a representação e a arreda do campo de pertinência da história da pintura moderna, e mesmo modernista ${ }^{35}$. Em segundo lugar, porque uma observação de telas como Entrada, nos permite verificar que a assimetria equacionada por França, não conforma senão distância, e uma distância que pode, na realidade, ser interpretada como distância crítica. Uma distância que, no caso de Entrada, joga também com referencias às colagens cubistas de Picasso.

Sublinhe-se então, para elucidar este último ponto, que ao mesmo tempo que potencia a lógica da colagem, Amadeo reivindica exclusivamente para o seu trabalho os meios da pintura. Vejam-se os fósforos no canto inferior direito da tela pintados como se de colagens de fósforos reais se tratassem. Mas veja-se sobretudo o modo como os papier collés são evocados em Entrada: os frutos representados sobre os pequenos recortes de papel, a lembrar decisivamente a colagem de Picasso de 1913, intitulada Bowl with Fruit, Violin, and Wineglass (hoje pertencente ao Philadelphia Museum of Art), adquirem na tela do pintor português um aspecto putrefacto que dificilmente pode deixar de entender-se como marcação de uma distância informada. Torna-se, como tal, impossível considerar estes elementos sem admitir que entre as múltiplas questões que Amadeo convoca para esta tela, e para além 
do dispositivo narrativo alimentado por referencias contextuais, Entrada conforma um território de reflexão crítica sobre a situação da pintura no seu tempo.

Esta hipótese é reforçada pelo tratamento dos discos simultâneos. Estes aparecem invariavelmente, nesta como em muitas outras telas deste período, como focos de atracção de pequenos insectos. Na lógica de colagem que Amadeo reinventa a partir do universo matérico da pintura, estes elementos pictóricos são refuncionalizados e surgem pois, por assim dizer, reduzidos a uma condição de "armadilha" para insectos voadores. Ainda que se admita, com França, a sua reinterpretação decorativa, tal reintrepretação impele-nos afinal a considerar a marcação clara de uma distância crítica, certamente lúdica e propriamente irónica, do pintor português em relação à "superior" função que os discos adquirem no esquema delaunayano. Uma distância, aliás, conforme, neste caso, com o grau de desapontamento a que as suas relações com os Delaunay o conduzem após a derrocada dos projectos comuns guizados em 1916.

É pois possível considerar que os meios da pintura empregues por Amadeo possam estar impregnados de uma potência crítica alicerçada pelo lugar regional de pertença, um lugar que lhe garantiu, enquanto actor do modernismo internacional, um ponto de observação privilegiado sobre correntes estabelecidas do seu tempo e, como tal, a possibilidade tomar assumir para o seu trabalho uma posição pictórica distanciada (e de novo crítica) dos feitos pictóricos que a historiografia modernista, ignorando a dimensão problemática dos debates em curso, contribuiu cegamente para hegemonizar.

\section{AGRADECIMENTOS}

Este artigo foi escrito em 2011 e é o primeiro de uma série de publicações que inclui também: 2012, “Criação, apropriação, deslocação (sobre a pintura de Amadeo Souza Cardoso)", Revista de História da Arte, N. 10 (práticas da teoria), 2012, pp. 111-127 (issn 1646-1762); e 2013, "Trapped bugs, rotten fruits and faked collages: Amadeo Souza Cardoso's troublesome modernism", Konsthistorisk tidskrift/Journal of Art History, N. 2, pp. 99-114 (Doi: 10.1080/00233609.2013.794859). Esta publicação enquadra-se no âmbito do projecto exploratório Modernismos do Sul/Southern Modernisms (EXPL/CPC-HAT/0191/2013) financiado pela FCT - Fundação para a Ciência e Tecnologia.

\section{NOTAS}

1 Para um resumo da biografia de Amadeo veja-se o Anexo 1. Para o aprofundamento dos dados apresentados consulte-se a Fotobiografia publicada pela Fundação Calouste Gulbenkian (2007).

2 Utilizo o conceito de Modernismo na sua formulação internacional mais ampla, canonizada na proposta crítica de Clement Greenberg em textos como Modernist Painters (1961).

3 J.-A. França escreve concretamente: "A guerra perturbou totalmente os planos de Amadeo, não tanto por interromper o fio das experiências que no próprio Verão de 1914 tinham sofrido alteração de rumo mas por deitar abaixo a estratégia que ele preparava, a nível internacional, e na qual tanto entrava Paris como a Alemanha (e até a Inglaterra, preparando-se também então para expor em Londres) - sítios que o conflito agora separava. A sua única realidade passou a ser a sua quinta de Manhufe, que era, para ele, algo de irreal, em comparação com a vida que deixava para trás" (França, 1985 [1957], 89).

4 É através de Almada que Amadeo entra em contacto com o grupo dos "Futuris- tas" lisboetas, reunidos inicialmente em torno da revista Orpheu (França, 1985 [1957], 119-122 e Ferreira, 1972).

5 Entendo por sério a qualidade de ter superado a abordagem biográfica dedicada ao culto do artista em termos que o sobrepõem à sua obra; os trabalhos que a historiografia dedica a Amadeo, correspondem, na sua maioria, ao que Rosalind Krauss classifica como a "história do nome próprio" (Krauss, 1996, 39 e ss).

6 "Junto de Robert e de Sonia Delaunay, os dois pintores portugueses [Eduardo Viana e Amadeo de Sousa Cardoso] trabalham, por assim dizer, reaccionariamente..." (França, 1968, 19).

7 Recorde-se que o título do artigo de Frampton nos reporta desde logo a uma perspectiva de resistência: "Hacia um regionalismo crítico: Seis puntos para uma arquitectura de resistencia".

8 António Ferro foi jornalista e editor da revista Orpheu. Dirigiu o Secretariado de Propaganda Nacional (SPN) do regime de Oliveira Salazar entre 1933 e 1949. É mentor da "política do espírito" que orientou a política cultural do Estado Novo atendendo ao que genericamente se designa como cultura popular (cf. Ó, 1999).

9 J.-A. França apresenta esta alteração do título original do livro de 1957 como problematizando a "categoria 'portuguesa' do artista (coisa que o título da 2a edição - "Amadeo ou o Século XX", de 1972 -ainda não elucidava). Assim, apesar da violência implícita na expressão "à força" (surgida como tradução insatisfatória do "malgré lui" francês), "o título Amadeo de Souza-Cardoso, o Português à Força apareceu com uma definitiva evidência - se entendermos essa força como a do Destino." E acrescenta: "Para além do nacionalismo caseiro que a certa altura (logo em 1925 num artigo de António Ferro) pretendeu tomar Amadeo à sua conta (...) havia o Destino que a essa aparência irremediavelmente o amarrou, fazendo-o morrer em Portugal, longe do Paris desnacionalizador." (França, 1985 [1957], 14-15)

10 Nas palavras de França: “'à força' também porque dessa imagem não chegou a poder desenvencilhar-se, mesmo na 
grande explosão da sua raiva. No 'colorido berrante' dela havia de se adivinhar a sempre referida pátria... Mas ainda e também 'à força', não por, em primeiras fumaças de imigrante, ter programado voltar mais tarde ao seu 'luminoso Portugal', mas porque isso convinha fundamentalmente e sem remédio ao processo mitológico, em que, pessoal, cultural, social e sacralmente, se definiu (...) Português então 'malegré lui', do que nele havia de 'parisiense', isto é, maugrado a sua necessidade de outros impulsos criativos. Para aquém da arte de vanguarda que criou, e da 'febre da vida moderna' que o atacou. Mas dentro do mito em que cristalizou." (França, 1985 [1957], 15)

11 Ou como se lê: "E não deixando igualmente de pôr a questão do grau de 'parisianismo' do pintor, isto é do seu grau de integração num universo cultural alheio, que a sua obra afinal, provando de mais, não chegará a provar." (Idem).

12 As palavras, bem conhecidas, são de Almada Negreiros e surgem no Folheto-Manifesto integrado no catálogo da exposição de Amadeo na Liga Naval em Lisboa (cf. Freitas, 2007, 248-249).

13 Seguindo aqui as palavras de Eduardo Lourenço em 1971, num texto que discutirei mais à frente (Lourenço, 1981, 135-136).

14 E ainda: "A técnica subtil de Delaunay não poderia, é claro, ser satisfeita por um principiante, alheio a toda a problemática pictoral que a tradição impressionista determinara na sensibilidade do 'orfismo' autêntico (...)" acrescentando que a crítica não deverá sublinhar exageradamente este facto porque Amadeo "fez o que pôde e mereceu elogio pelo resultado obtido, demonstrando mesmo uma inesperada capacidade" (França, 1985 [1957], 139).

15 "Many consider that decorative preoccupations must govern the espirit of the new painters. Undoubtedly they are ignorant of the most obvious signs which make decorative work the antithesis of the picture. The decorative work of art exists only by virtue of its destination; it is animated only by the relations established between it and the given objects. (...) A painting carries within itself its raison d'être." (Gleizes e Metzinger, 2004 [1912], 95).

16 Em 1968, a apropriação dos discos simultâneos é equacionada a partir do contraste entre o "modo" de Eduardo
Viana e o de Amadeo nos seguintes termos: "Algures marquei o sentido de adaptação estrutural dos 'discos' dos Delaunays que Viana se esforçou por 'coisificar', dentro da sua tendência mais sensual; algures também assinalei o mero sentido decorativo que os mesmos 'discos' ganharam nas composições de Amadeo. Num pintor temos então uma valorização interna e no outro uma valorização exterior, do mesmo signo e em ambos um curioso alheamento do sistema em que o signo originariamente funcionava." (França, 1968, 18).

17 Já em 1968 escrevera: “A análise das composições de Viana e de Amadeo dentro do esquema dos 'discos' mostranos claramente que a originalidade que devemos atribuir-lhes tem um valor negativo. Isto é: através dela transparece apenas uma ignorância uma ingenuidade mental, perante o fenómeno considerado." (França, 1968, 18-19).

18 Há aqui uma transformação importante da sua posição em 1968 em que os "discos" eram ainda "dos Delaunays" e não apenas de Robert Delaunay.

19 E escreve mais considerando a obra de Amadeo: "Do folclore, adaptado ao seu Norte, num momento de euforia, à velocidade que por outra via também o fascinara, Amadeo entendeu assim o uso decorativo dos 'discos' vistos em Montparnasse e revistos em Vila do Conde, nos dois pólos da sua vida de nortenho em Paris, em torna-viagem. E em relação a essas duas experiências, elas seriam ainda um sinal de reconhecimento, uma lembrança, um elo, um exílio de guerra de Amadeo. Algo que ligava Portugal à Europa, embora só decorativamente, como podia ser - e antes de em ligação alguma ele poder acreditar, ou de qualquer ligação desejar..." (França, 1985 [1957], 140).

20 "Para Viana era preciso que um "disco" se justificasse como coisa inscrita num circuito de outras, plásticamente solidárias - e se acordasse, p. ex., com o corpo e a cara de uma figura, ou fosse mesmo garantido por um alguidar de bom barro popular, luzindo-lhe no fundo... (...) A "coisificação" essencial da pintura de Viana, altamente interessante como pesquisa própria, mantém estruturas naturalistas ou substantivas (de certo modo portuguesmente próximas de Malhoa) que, por outro lado, a arredam da pintura de Amadeo" (França, 1985 [1957], 141).

21 Para uma extensão desta questão no quadro do pensamento de J.-A. França, veja-se a análise de Catarina Crua ao inquérito "O Problema da Cultura Portuguesa" publicado na Bicórnio em 1952 (Crua, 2011, 52-52).

22 Veja-se particularmente o capítulo "Modernidade, identidade e cultura de fronteira". As hipóteses de trabalho que o sociológo coloca são assaz relevantes. Marcam uma reacção forte contra o discurso identitário e o que designa por "excesso de interpretação mítica" da identidade nacional, abrindo uma perspectiva a que regressarei mais tarde $\mathrm{e}$ que foi recentemente pontuada também pelo trabalho de Silvina Rodrigues Lopes (2007).

23 "Os discursos convencionais sobre a 'identidade nacional' têm sido construídos a partir de um genius loci mitificado abstracto e mistificador e os mais recentes têm-nos glosado (ou pouco mais) (...), com a excepção, nem sempre conseguida, de Eduardo Lourenço." (Santos, 1994, 54). Como demonstra Silvina Rodrigues Lopes (2007, 54-86), Portugal Hoje. O Medo de Existir de José Gil é um digno herdeiro destes discursos.

24 Suportando esta ideia está a constação de que as "culturas nacionais, enquanto substâncias, são uma criação do século XIX, são, como vimos, o produto histórico de uma tensão entre universalismo e particularismo gerido pelo Estado. 0 papel do Estado é duplice: por um lado, diferencia a cultura do território nacional face ao exterior; por outro lado, promove a homogeneidade cultural no interior do território nacional . A minha hipótese de trabalho é que, em Portugal, o Estado nunca desempenhou cabalmente nenhum destes papéis, pelo que, como consequência, a cultura portuguesa teve sempre uma grande dificuldade em se diferenciar de outras culturas nacionais, ou, se preferirmos, uma grande capacidade para não se diferenciar de outras culturas nacionais e, por outro lado, manteve até hoje uma forte heterogeneidade interna. $\mathrm{O}$ facto de o Estado português não ter desempenhado cabalmente nenhuma das duas funções - diferenciação face ao exterior e homogeneização interna - teve um impacte decisivo na cultura dos Portugueses, o qual consistiu em as espáciotemporalidades culturais local e transnacional terem sido sempre mais fortes do que a espácio-temporalidade nacional." Explica também: "A manifestação paradigmática desta matriz intermédia, semiperiférica, da cultura portuguesa está no facto de os Portugueses terem sido, a partir do século XVII, (...) o único 
povo europeu que, ao mesmo tempo que observava e considerava os povos das suas colónias como primitivos ou selvagens, era, ele próprio, observado e considerado, por viajantes e estudiosos dos países centrais da Europa do Norte, como primitivo e selvagem." (Santos, 1994, 132-133).

25 "Para as culturas dotadas de fortes centros, as fronteiras são pouco visíveis, e isso é a última causa do seu provincianismo. Ao contrário, o acentrismo da cultura portuguesa é o outro lado do seu cosmopolitanismo, um universalismo sem universo feito da multiplicação infinita dos localismos" (Santos, 1994, 134).

260 próprio Boaventura Sousa Santos o faz quando, por exemplo, fala do fenómeno de "carnavalização da política" (cf. Santos, 1994, 61-63).

27 “Uma ferramenta não é, não pode ser uma simples gaveta de arquivo e, seja em que campo for, a sua bondade e pertinência dependem sempre da utilização que lhe é dada. Uma coisa será detectar na obra daqueles ou de outros autores sintomas de uma atitude atenta a vectores de um 'regionalismo', formulação esta maleável, de âmbito puramente critico ela também, em que já nem sequer interessa saber se o autor está ou não de acordo, porque a obra vive independente do seu autor e permanece aberta às leituras críticas que dela queiramos fazer. Outra bem diferente e muito questionável será querer entender o regionalismo crítico, enquanto categoria para classificar autores tendo em vista a comodidade e simplificação de enquadramento. No campo interpretativo-crítico, creio que a ideia de Frampton se constituiu inegavelmente como uma sólida contribuição. Até na prevenida e clara rejeição de uma interpretação articulada com qualquer populismo de teor mais ou menos romântico. Suponho portanto ter sido importante esse genérico conferir nome a uma sensibilidade que permanecia difusa e dispersa." (Almeida, 2007, 83-84).

28 Pedro Lapa é o autor que primeiro sustenta esta hipótese considerando a obra de Amadeo; escreve: "The place of enunciation of Amadeo Souza Cardoso' $s$ project is drawn up on this edge of the dominant cultural value, without having a specifically constituted and identity-oriented cultural alterity as a reference." $E$, orientando-se para a leitura de obras específicas como Procissão do Corpus Christi, Canção Popular e o pássaro do Brasil e Canção popular a russa e o Figaro: "Among signs of a local culture - the Minho region of his birth - and those of an avant-garde transnational culture - with marks of cubism, futurism and orphism - there is a hybrid aspect characteristic of this forntier culture. The ease in articulating a local (regional) specificity with an international, centralist, hegemonic context is a clear example of this national characteristic." (Lapa, 1999, 107-108).

29 A noção, fixada no subtítulo do artigo de Frampton, é caracterizada por Pedro Vieira de Almeida nos seguintes termos: "Mas responsável e gravemente, aquela estratégia de resistência (...) opõe-se a uma visão cultural, assutadoramente niveladora, global, 'totalizante'. Visão em que a partir de reconhecidos ou autopromovidos centros culturais, noções de arquitectura são soberanamente distribuídas às periferias, num gesto largo que alardeia a duvidosa generosidade de quem se limita a alimentar capoeiras culturais. Podemos polidamente recusar o alimento. É que em definitivo só é bicho de capoeira quem quer." (Almeida, 2007, 85).

30 Creio que isso nos permite compreender que sendo acérrimo defensor do moderno, no sentido rimbaudiano do termo, o autor declare o seu ódio ao modernismo (cf. França, 1956).

31 Nas palavras de Kenneth Silver: "'foreign-ness' became a kind of nationality of its own in early-twentienth-century Paris, a cosmopolite identity of both self assured belonging and undeniable difference" (Silver,1999, 55). Ver também Marjory Perloff (2003 [1986]).

32 "Growing fears of international and inter-class conflict ensured that the traditionalist and solidarist discourses were dominant in the literary and artistic avant-garde formation as they were in society at large, and contributed crucially to the pre-war hegemony of Radicalism. Yet the reality of any hegemony is that is never total or exclusive, and the artistic avant-garde was also one of the primary sites of resistance to nationalist pressures; first because of its cosmopolitan character - the émigrés who were preponderant in many of its milieux had little incentive to rally to the tricolore - and second, because the collapse in 1905 of the Bloc des Gauches left its participants with diminished interest in politics. For the émigrés, self-referenciality and isolation encouradge a notion of the artist as necessarily estranged; for those whose attempts at class collaboration had ended in desillusionment, the idealism that had driven them was tranferred to aesthetic practice. Fot both, resistance was grounded in the values of art in and for itself, as uniquely free from commodification and instrumentality.This was the discourse of aestheticism." (Cottington, 1998, 5)

33 Uma cegueira de algum modo antitética da que D. Arasse (2000) ou H. Damisch (1993 [1987]), por exemplo, denunciam e discutem, mas que, quando falamos da historiografia do modernismo, parece ocupar uma posição simétrica à da vertigem descodificadora das investidas iconográficas ou das versões da teoria do reflexo dominantes em muita história social da arte.

34 Veja-se no Catálogo Raisonné. Fotobiografia (2007: 278) a imagem no 9 legendada como "Provável maqueta para a pintura Sem Título (ENTRADA) [Amadeo, 1917-1918]. Espólio ASC-BA".

35 Um dos pontos centrais da revisão que J. Rancière (2010) faz dos pressupostos da modernidade passa por esta questão. Defende Rancière que a ruptura com a mimesis não significou de modo algum o fim da figuração. Estabelecer uma linha de ruptura entre o representativo, o não-representativo e o antirepresentativo, escreve, reporta-se a uma historicização simplista sustentada na "passagem à não figuração que ocorreu na pintura". Essa passagem foi teorizada "com base numa assimilação sumária a um destino global antimimético da 'modernidade' artística", destino esse que sustentou a redução dessa modernidade ao esvaziamento da sua autoproclamação, como famosamente fez Clement Greenberg. 
Almeida, Pedro Vieira de (2007): Apontamentos - para uma teoria da arquitectura, Lisboa, Horizonte.

Arasse, Daniel (2000): On n'y voit rien: Descriptions. - Paris: Folio.

Arnaldo, Javier (2008): 1914! La vanguardia y la gran guerra. - Madrid: Museo Thyssen-Bornemiza.

Crua, Catarina (2011): Revistas Córnio: Modernidade e Discurso Crítico na Cultura Portuguesa da Primeira Metade do Século XX, Lisboa, FCSH-UNL (dissertação de mestrado).

Damisch, Hubert (2007): "Hubert Damisch entrevistado por Joana Cunha Leal”, Revista de História da Arte. - N. 3.

Ferreira, Paulo (1972): Correspondance de quatre artistes portugais, Paris, PUF.

Ferro, António (1925): "Os artistas do salão de Outono", Diário de Noticias, (16 Dezembro).

Frampton, Kenneth (1985): “Hacia um regionalismo crítico: Seis puntos para uma arquitectura de resistencia", La Postmodernidad (ed. Hal Foster), BarceIona, Kairos.

França, José-Augusto (1985 [1957]): “Amadeo de Souza-Cardoso, o Português à Força", Amadeo \& Almada, Venda Nova, Bertrand.

França, José-Augusto (1997 [1974]): “O 'facto artístico' na sociologia da arte", (In)definições de Cultura, Lisboa, Presença.
França, José-Augusto (1968): “Amadeo (e Santa Rita) 1918-1968", Colóquio: revista de artes e letras, N. 51 (Dezembro).

França, José-Augusto (1956): "Il faut être absolument moderne, Rimbaud", Pentacórnio, Lisboa, s.n.

Freitas, M. Helena, ed. (2007): Catálogo Raisonné Amadeo Souza Cardoso: Fotobiografia - Volume I, Lisboa, FCG.

Freitas, M. Helena (2006): “Amadeo de Souza-Cardoso, Diálogo de Vanguardas", Diálogo de Vanguardas, Lisboa, FCG-CAM.

Gonçalves, Rui Mário (2006): Amadeo de Souza-Cardoso: A ânsia de originalidade, Lisboa, Caminho.

Krauss, Rosalind (1996 [1985]): La originalidad de la Vanguardia y otros mitos modernos, Madrid, Alianza Forma.

Krauss, Rosalind, (1985): "La escultura como campo expandido", La Postmodernidad (ed. Hal Foster), Barcelona, Kairos.

Lapa, Pedro (1999): “A Modernist Through the Memory of a Distant Present", At the Edge: A Portuguese Futurist, Lisboa, GRI, Corcoran Gallery.

Lopes, Silvina Rodrigues (2007): "Resistir às máquinas identitárias”, Intervalo. - N. 3 - A Fuga (Maio).

Lourenço, Eduardo (1981): O Espelho Imaginário. Pintura, anti-pintura, não pintura, Lisboa, IN-CM.

Ó, Jorge Ramos do (1999): Os anos de Ferro, Lisboa, Estampa.
O'Neill, Rosemary (1999): “Modernist Rendez-vous: Amadeo de Souza Cardoso and the Delaunays", At the Edge: A Portuguese Futurist, Lisboa, GRI, Corcoran Gallery.

Perloff, Marjory (2003 [1986]): The Futurist Moment: Avant-Garde, Avant-Guerre, and the Language of Rupture, Chicago, The University of Chicago Press.

Pessoa, Fernando (2001): Crítica - Ensaios, Artigos e Entrevistas, Lisboa, Assírio e Alvim.

Rancière, Jacques (2010): Estética e Política: A Partilha do sensivel, Porto, Dafne.

Santos, Boaventura Sousa (1994): Pela Mão de Alice. O Social e o Político na Pós-Modernidade, Porto, Afrontamento.

Santos, Mariana Pinto dos (2010): “'Estou atrasado! Estou atrasado!' - Sobre o atraso da arte portuguesa diagnosticado pela historiografia", Representações da Portugalidade, Covilhã, Universidade da Beira Interior [no prelo]

Santos, Rui Afonso (1999): “Entrada”, At the Edge: A Portuguese Futurist, Lisboa, GRI, Corcoran Gallery.

Silver, Kenneth (1999): "Amadeo in the Tower of Babel", At the Edge: A Portuguese Futurist, Lisboa, GRI, Corcoran Gallery.

Silver, Kenneth (1989): Esprit de Corps: The Art of the Parisian Avant-Garde and the First World War, 1914-1925, London, Thames and Hudson. 


\section{ANEXO 1- NOTA BIOGRÁFICA}

a113 Amadeo nasceu na quinta dos seus pais em Manhufe (Amarante, Portugal) a 14 de Novembro de 1887. Cresceu entre 9 irmãos, no seio de uma família de proprietários rurais. Passou a sua infância entre a casa de Manhufe e as estâncias de veraneio na praia de Espinho. Ai conheceu Manuel Laranjeira cuja amizade foi determinante para incentivar a prática do desenho, prática que Amadeo desenvolveu em Lisboa no âmbito dos estudos preparatórios de Arquitectura na Academia de Belas Artes de Lisboa iniciados em 1905.

A viagem para Paris em Novembro do ano seguinte não tinha data de regresso. Financiado pelos pais, Amadeo instalou-se no Boulevard Montparnasse para prosseguir os estudos de Arquitectura na École des Beaux Arts. Contudo, o ambiente parisiense reforçou a sua inclinação para o desenho e a caricatura, contribuindo para afastá-lo de vez do campo da Arquitectura. Particularmente influenciado pela ilustração que circulava na imprensa francesa, Amadeo não tardará a dedicar-se ao desenho e à pintura.

Os primeiros anos de estadia em Paris ficaram marcados pelo convívio com outros portugueses emigrados. O estúdio que alugou no 14, Cité Falguière converteu-se num espaço de tertúlias e boémia com a presença assídua de artistas como Manuel Bentes, Eduardo Viana (que o acompanhará em 1907 numa viajem à Bretanha), Emmérico Nunes, Domingos Rebelo e Smith.

O final de 1908 e o início do ano seguinte trazem importantes alterações à vida de Amadeo: conhece Lucia Pecetto, com quem casará em 1914, e começa a frequentar as classes da Academia Viti, do pintor espanhol Anglada-Camarasa. Muda então o seu atelier para a rue des Fleurus num espaço contíguo ao apartamento de Gertrude Stein. Estas alterações terão contribuido para distanciá-lo do circuito dos artistas portugueses. Mas esse afastamento voluntário traduzia também um corte de sentido plástico, uma vontade de romper com a "rotina atrasada" que lhes atribui. Amadeo mergulhava então plenamente nas pesquisas do modernismo internacional em desenvolvimento em Paris. É nesse contexto que, em 1910, o veremos entusiasmado com as pinturas dos "primitivos" flamengos (numa estadia de 3 meses em Bruxelas). É neste período também que o veremos aprofundar a sua amizade com Amedeo Modigliani.
Em 1911, Amadeo muda outra vez de estúdio. Instala-se próximo do Quai d'Orsay, na rue du Colonel Combes. Em Outubro realiza neste espaço uma exposição com Modigliani. Esta não seria, contudo, a primeira exposição da sua obra. Alguns meses antes, Amadeo apresentara um conjunto de 6 pinturas no Salon des Indépendents. Volta a expôr neste Salão no ano seguinte e em 1914. De igual modo, mostra o seu trabalho no Salon d'Automne entre 1912 e 1914. Entretanto, o seu círculo de amizades e conhecimentos estende-se e internacionaliza-se. Conhece Umberto Boccioni, Gino Severini, e Walter Pach, que mais tarde o convidará a participar no Armory Show. Está também em contacto com Juan Gris, Max Jacob, Sonia e Robert Delaunay, Brancusi, Archipenko, Umberto Brunelleschi e Diego Rivera, entre outros.

O interesse de Amadeo pelo desenho consolida-se neste período com a preparação do manuscrito ilustrado da Légende de Saint Julien L'Hopitalier de Flaubert e pela publicação do álbum XX Dessins com prefácio de Jerôme Doucet, álbum que mereceria uma apreciação muito favorável do célebre crítico Louis Vauxcelles.

Amadeo esforçar-se-á também por mostrar a sua pintura fora do circuito parisiense. Os contactos que estabelece nestes anos permitir-lhe-ão participar numa série de importantes exposições colectivas, entre as quais a Exposição Internacional de Arte Moderna de 1913, também conhecida como Armory Show, que mostraria pela primeira vez a moderna arte europeia nos EUA (Nova lorque, Chicago e Boston). Amadeo apresenta um total de 8 obras, ao lado de Braque, Matisse, Duchamp, Gleizes, Herbin y Segonzac. Três das suas telas foram compradas pelo coleccionador de Chicago, Arthur J. Eddy, o qual, ao publicar Cubist and Post-Impressionism (1914), cita e reproduz algumas das obras do pintor português, destacando-o pelo seu colorido. Outros importantes contactos vão levá-lo à Alemanha. Em Setembro de 1913, já depois de outra mudança de estúdio (que o leva a instalarse em Montparnasse, na rua Ernest Cresson), estará representado no I Herbstsalon de Berlim, organizado pela Galeria Der Sturm. Amadeo já havia trabalhado com esta galeria berlinense em Novembro de 1912, data em que pela primeira vez expôs no seu espaço. É muito provável que em 1914 tenha participado em mostras em Colónia e Hamburgo e é certo que em Abril desse mesmo ano enviou 3 trabalhos para a 
Royal Academy de Londres, tendo todavia a exposição sido cancelada com o deflagrar da Guerra.

Também em 1914, antes de deixar Paris para passar o Verão em Portugal, como era habitual, Amadeo volta a mudar de atelier para a Vila Louvat, no no38 bis da rua Boulard. Não chegou todavia a utilizar este espaço. Após uma breve passagem por Barcelona em que visita o seu amigo, escultor, António Sola, e conhecerá Gaudí, Amadeo regressa a Manhufe onde será surpreendido pelo deflagrar da Guerra que o impedirá de regressar a Paris.

A estadia forçada de Amadeo em Portugal não foi sinónimo de apatia criativa. Se ainda em Paris a sua obra explorara os domínios da abstracção e, depois, enveredara por vias de compromisso expressionismo, o exílio em Portugal acabará por constituir-se como um momento de plena maturação da sua pintura que se aproximará então de muitas das questões equacionadas no domínio colagem.

Em 1915, o isolamento de Amadeo em Amarante foi quebrado pelo contacto com Sonia e Robert Delaunay que a Guerra fizera também, inesperadamente, aportar a Vila do Conde. Por esta via, o círculo das suas relações recupera Eduardo Viana alarga-se a Almada Negreiros. No seio deste núcleo de amizades geramse diversos projectos, nomeadamente a criação de uma Corporation Nouvelle destinada a promover exposições internacionais itinerantes, ideia que nunca chegou a concretizar-se. Entretanto, através de Almada, Amadeo entra em contacto com o grupo dos "Fu- turistas" lisboetas, reunidos inicialmente em torno da revista Orpheu.

$\mathrm{Na}$ batalha pela agitação do meio artístico português, Amadeo teve um papel discreto, mas relevante. No final de 1916, numa conhecida entrevista que deu ao jornal O Dia, parafraseia largamente os manifestos de Marinetti. Não que as propostas do Futurismo o cativassem enquanto solução formal. A postura radical, modernista, nacionalmente identificada com o movimento, convieram todavia a Amadeo como forma de intervenção e motor de ruptura com as estruturas tradicionalistas dominantes e que haviam atacado por ocasião das suas duas únicas exposições realizadas em vida em Portugal.

Em Dezembro de 1916 Amadeo promoveu, primeiro no Porto e depois em Lisboa, uma mostra em que reuniu sob o título de Abstraccionismo 114 pinturas. O desfasamento da cultura estética nacional impediu uma recepção favorável das propostas pictóricas de Amadeo, ganhando os certames uma aura de escândalo (coroada no limite pela agressão física ao pintor). Neste contexto importa destacar o protagonismo de Almada Negreiros e Fernando Pessoa na defesa pública do pintor. Ambos o reconheceram como o pintor mais significativo do seu tempo. Mas não deixaram de ser manifestações excêntricas e isoladas.

Amadeo morreu em Espinho em Outubro de 1918 vítima da epidemia de pneumónica que deflagrou nesse ano. Tinha apenas 30 anos. 